\title{
“ARE YOU THERE, TRADEMARK LAW? IT'S ME, MISOGYNY."
}

\author{
ANN BARTOW*
}

\section{INTRODUCTION}

When I became aware of the emergent body of legal scholarship on menstruation related topics on which this Symposium builds, I thought that the authors of these articles were very brave. ${ }^{1}$ I'm an imperfect but life-long feminist and accepted the emotional challenge that writing this Essay posed for me out of gratitude to those authors. Because my principal scholarly focus is intellectual property law, I approached the topic through the lens of trademark law. Part One of this article positions this Essay firmly within the contours of the author's life and personal experiences with menstruation. Part Two maps common trademark and branding practices related to tampons and sanitary napkins. Part Three explains that the Lanham Act does not offer legal mechanisms by which to challenge the federal registration of sexist trademarks. As with racist trademarks, amplified criticism and persistent public pressure are the main mechanisms available to foment positive change in the marketplace for feminine hygiene products.

\section{Menstruation, Manipulation, and Shame}

The book “Are You There God? It's Me, Margaret” by Judy Blume had a profound effect on me when I was around eight or nine years old. I used my own money to buy a stealth copy after being left unsupervised in a mall bookstore and found the story both

\footnotetext{
* Professor of Law, University of New Hampshire Franklin Pierce School of Law. This Essay is dedicated to Casey Bartow-McKenney. The author thanks the Columbia Journal of Gender and Law for the kind invitation to participate in this "Are You There Law? It's Me, Menstruation" Symposium, and Bridget Crawford for very helpful editorial comments.

${ }^{1}$ See, e.g., Jennifer Bennett, The Tampon Tax: Sales Tax, Menstrual Hygiene Products, and Necessity Exemptions, 1 Bus. ENTREPRENEURSHIP \& TAX L. Rev. 183 (2017); Lauren Shaw, Bloody Hell: How Insufficient Access to Menstrual Hygiene Products Creates Inhumane Conditions for Incarcerated Women, 6 Tex. A\&M L. Rev. 475 (2019); Christopher A. Cotropia \& Kyle Rozema, Who Benefits from Repealing Tampon Taxes? Empirical Evidence from New Jersey, 15 J. EMPIRICAL LEGAL STUD. 620 (2018); Molly Minta, Is the Tax on Tampons Unconstitutional?, THE NATION (Oct. 1, 2019), https://www.thenation.com/article/archive/menstrual-equity-tampon-tax/ [https://perma.cc/D7FR-HM6G]; Bridget Crawford \& Carla Spivack, Human Rights and Taxation of Menstrual Hygiene Products in an Unequal World, in TAX, INEQUALity, AND Human Rights (Philip G. Alston and Nikki Reisch eds., Oxford University Press 2019); Bridget J. Crawford \& Carla Spivack, Tampon Taxes, Discrimination and Human Rights, 2017 Wisc. L. REV. 491 (February 21, 2017).
} 
compelling and confusing. I knew nothing of puberty or menstruation. I didn't have any close friends with older sisters, and the topic had never been raised with me by my parents or anyone else. But somehow, I knew I needed to read that book.

After I'd read it at least three times, I lent it to a similarly clueless friend who had once showed me a wrapped tampon, and said she thought it was "something mothers have to shove up their butts to keep their heinie holes open." We dared not unwrap it, and all we could feel through the paper cover was a plastic tube. Her mother caught her with my copy of "Are You There God, It's Me, Margaret" and called my mother about it. To my mother's credit, she read the book before confronting me about it. The stupid lie I was going to tell - that I bought the book because the main character was named Margaret, my mother's own name - turned out to be unnecessary. She wasn't angry at me and she was fascinated by the book. But she had a really difficult time talking to me about menstruation, and we have never to this day discussed sex or birth control. I felt a lot of shame and fear about all of those topics as a teenager, and I'm not entirely over it.

When I got my first period at age thirteen, it made my parents very uncomfortable. My father instructed me to wrap my used sanitary napkins thoroughly in toilet paper and then put them in an outdoor trashcan. He did not want to encounter any evidence that I was menstruating. When I got a small notebook to keep track of my menstrual cycle, I marked the cover only with a large dot (a period!) so that if anybody else saw it they would not know the meaning of the dates inside.

I changed sanitary napkins very frequently because I did not want to smell like blood. ${ }^{2}$ My family did not have a lot of money, and my mother constantly reprimanded me for using "too many" sanitary napkins, so I was always worried about supply. I sometimes bought some back up pads with my babysitting money and hid them in my room, but the first time that stash got depleted, I swiped some of my mother's tampons and learned how to use them. And then there were those terrible days when I went to school with a giant wad of toilet paper in my pants, several changes of underwear, and pockets filled with coins that I could use to buy napkins from the machine in the girls' restrooms.

\footnotetext{
${ }^{2}$ Technically I did not want to smell like menstrual fluid, which is made up of blood, vaginal secretions, cervical mucus, and tissue from the endometrium. See generally Michael S. Burnhill \& Charles H. Birnberg, The Contents of Menstrual Fluid: An Analysis of 260 Samples from Human Females, AM. J. OBSTETRICS \& Gyn. 92:2, 183 (1965); Korin Miller, This Is What's Actually In Your Period Blood, SELF (July 15, 2016), https://www.self.com/story/this-is-whats-actually-in-your-period-blood [https://perma.cc/N5CR-59YP].
} 
One day I inserted a pilfered tampon only to realize that it had a manufacturing defect and lacked a string. This put me into a panic, and I convinced a friend to drive me to the Planned Parenthood in a neighboring town so that I could get medical assistance. When I got into the stirrups for the very first time in my life, and explained my difficulty to the nurse, she asked me, "Why didn't you just reach in and pull it out yourself?" The terrified look she got from me in response led to one of the most important conversations I have ever had in my life. She fished out the stringless tampon with a speculum, and firmly told me I needed to become more familiar and comfortable with my body. She advised me to touch myself everywhere, without shame, so that I could figure out what was where and how things worked. She also suggested that I buy a copy of "Our Bodies, Ourselves,"3 which was terrific advice. Not only did I learn a lot from the book, but I found out that some of my friends also had copies, which was an icebreaker for some very frank and helpful conversations about birth control, sex, and boys. Still, we never discussed menstruation beyond noting when we had our periods, worrying that we hadn't gotten our periods, or complaining about cramps.

\section{Menstruation, Trademarks, and Branding}

In a recent essay published in the New York Times, the author observed that while her preteen daughter watched an hour long "period film" at school, it was not shown to the boys, because they were deemed "not ready."4 Pornography can be the primary or even only "sex education" that young people receive. ${ }^{5}$ I suspect it is rare indeed that pornography teaches accurately about fertility and menstruation. Most of my early education - and miseducation - about menstrual products came from advertisements. For example, when a commercial informed me that "o.b." tampons were invented by a female gynecologist, I was impressed but confused. I knew what an O.B./G.Y.N. was, even though I had never seen one. Since o.b. is a common abbreviation of "obstetrician," I wondered why they weren't called "g.y.n" tampons instead. When you require an obstetrician, you do not usually need tampons. But it turns out that the o.b. in o.b. ${ }^{\circledR}$ brand

\footnotetext{
${ }^{3}$ Boston Women's Health Book Collective, Our Bodies, Ourselves (Touchstone 5th ed. 2011).

${ }^{4}$ Samantha Hunt, What Is a Teenage Girl? Feeling Things Is an Act of Bravery, N.Y. TimEs (Jan. 22, 2021), https://www.nytimes.com/2021/01/22/opinion/kamala-harris-girls.html [https://perma.cc/E4CK-4M7G].

${ }^{5}$ Kath Albury, Porn and Sex Education, Porn as Sex Education, Porn STUdies 172 (2014); John Chirban, Pornography: The New Sex Ed For Kids, Psych. Today (Dec. 15,

2012), https://www.psychologytoday.com/us/blog/age-un-innocence/201212/pornographythe-new-sex-edkids [https://perma.cc/83Q2-RV78]; Brian McNeill, How Pornography Influences and Harms Sexual Behavior, MED. XPRESS (Jan. 27, 2015), https://medicalxpress.com/news/2015-01-pornography-sexualbehavior.html [https://perma.cc/84XU-5PH9].
} 
tampons actually stand for "ohne binde" in German, which means "without napkins." Nevertheless, the company overtly ties its tampons to medical science in its origin story:

It all began 50 years ago with German gynecologist Dr. Judith Esser's personal quest for a smarter tampon. Her fruitless search led her to develop her own tampon design, one that was easy to use, comfortable, and (most importantly) provided great protection. To this day, the o.b. ${ }^{\circledR}$ brand continues to retain a board-certified gynecologist and research teams to pursue Esser's vision for creating safe, effective, and innovative options for women. ${ }^{7}$

Without good quality sex education as a counterpoint, I was heavily influenced by the marketing campaigns around feminine hygiene products. I ascertained that I was supposed to douche, even though douching can lead to many health problems, including infertility, vaginal infections, and sexually transmitted infections. ${ }^{8}$ I learned that Summers Eve Fresh Scent ${ }^{9}$ Douche "has been gynecologist tested for gentleness," "will leave you feeling clean and fresh," and unlike Summers Eve's insipid commercials, the product would "make sure you're getting the proper attention you so rightly deserve without irritation." ${ }^{.10}$ I learned that tampons were suitable for surfing and horseback riding, ${ }^{11}$ and that one particular brand had been found to give "super comfort and super plus protection" in tests that were supervised by doctors. ${ }^{12}$ I heard about all manner of sprays, "cleansing washes," and scented clothes intended to make my vagina smell like "Sweet Oasis," "Golden Glamour," "Blissful Escape," "Tahitian Sunset," or many other

${ }^{6}$ The O.B. Tampon Story, O.B. (2020), https://www.ob-tampons.com/faq/about-ob-tampons [https://perma.cc/N982-3QTS].

${ }^{7} I d$.

${ }^{8}$ Office on Women's Health, Dept. of Health and Human Services, Douching (Apr. 1, 2019), https://www.womenshealth.gov/a-z-topics/douching [https://perma.cc/5ABJ-MJCD].

${ }^{9}$ Also currently available in "Sweet Romance" and "Island Splash." Fresh Scent Douche, SummER's Eve, https://www.summerseve.com/summers-eve/fresh-scent-douche [https://perma.cc/Q6TT-UWCZ], [hereinafter, Summer's Eve].

${ }^{10} I d$.

${ }^{11}$ Tampax. 1982. Wind Surfing, Horseback Riding Etc., YouTube (June 2, 2013), https://www.youtube.com/watch?v=cQuc5Y5k6mE [https://perma.cc/ZN5X-2ZW4].

12 Tampax Tampons Commercial 1980, YouTuBe (May 20, 2011), https://www.youtube.com/watch?v=XudcJyHmzQ0 [https://perma.cc/ML6P-9W8V]. 
chemical scents. ${ }^{13}$ I was supposed to smell like anything except myself, with a strong floral trend in evidence among the scented options.

Most powerfully of all, I learned that I was supposed to hide any evidence that would suggest I was menstruating. And I am far from alone in this. ${ }^{14} \mathrm{~A}$ few years ago, the prestigious science publication Nature contained an article entitled: "Fighting the menstruation taboo in the field" in which field researchers discussed the challenges of menstruating in geographically remote areas. ${ }^{15}$ These challenges were primarily caused by a lack of privacy and "a macho culture in the field that might not consider coping with menstruation sufficiently "tough." "16 The article was intended to "help to raise awareness that periods shouldn't be a taboo topic," and to reduce the stigma so that people could feel more comfortable discussing menstruation. ${ }^{17}$ One interested observer noted:

How American woman manage and approach menstruation is called the "modern period," according to historian Lara Freidenfelds. She explains the concept in her 2009 book, "The Modern Period: Menstruation in Twentieth-Century America." "It's the idea that your body does not undermine your ability to be productive at school or at work," Freidenfelds said in an interview. "It's a body that doesn't smell or have cramps." At the turn of the 20th Century, women wore cloth diapers to manage their flow. By the 1920s, women entering the burgeoning pinkcollar job market felt pressure to be discreet and presentable. ... Ads played a large part in shaping the "modern period." As part of Freidenfelds' research, she delved into archives of Kotex advertising campaigns. To develop a brand that is trustworthy to women and girls, Kotex hired professional nurses to create educational materials about menstruation. ${ }^{18}$

\footnotetext{
${ }^{13}$ See, e.g., Products, SUMmER's Eve, https://www.summerseve.com/feminine-hygiene-products [https://perma.cc/329B-TZQC].

${ }^{14}$ Rachel Hatzipanagos, Why We're Taught to Hide Our Periods, THE LiLy (June 14, 2017), https://www.thelily.com/why-were-taught-to-hide-our-periods/ [https://perma.cc/SGN9-JEJM].

${ }^{15}$ Rachel Becker, Fighting the Menstruation Taboo in the Field, NATURE (Feb. 12, 2016), https://www.nature.com/articles/nature.2016.19372 [https://perma.cc/3RQW-KDWU].

${ }^{16} I d$.

${ }^{17} I d$.

${ }^{18}$ Hatzipanagos, supra note 14.
} 
Stigmas around menstruation are not unique to the United States, ${ }^{19}$ and are worse in other countries. ${ }^{20}$ Thanks to almost universal patriarchy, menstruation is associated with impurity among most of the world's religions and cultures. ${ }^{21}$

\section{A. The Intangible Value of Trademarks}

People will pay more for a product with an appealing trademark than for a store brand, even if the products inside the packaging are identical. Consider the wide range of price points associated with plain bottled water. Ounce for ounce people pay more for bottled water than they do for gasoline. ${ }^{22}$ People will pay premium prices for water that has a fancy container and an alluring trademark, even though the consumable contents are usually identical to the cheapest brand, and indistinguishable from water that flows through sinks and water fountains at very low prices. In fact, many beverage companies simply bottle tap water, ostensibly after passing it through a filter. ${ }^{23}$

In the 1970 s and 80 s, Wisk brand detergent garnered visibility and success ${ }^{24}$ from a series of commercials in which a male would be accused of having "Ring Around the

\footnotetext{
${ }^{19}$ See, e.g., Olivia Willis, Breaking the Menstrual Taboo: Why Period Stigma Still Holds Women Back, ABC News (Sept. 29, 2017, 5:28 PM), https://www.abc.net.au/news/health/2017-09-30/menstrual-cycle-tabooholds-women-back/8996526 [https://perma.cc/EWK2-97G9].

${ }^{20}$ Mustapha Ben Messaoud, Man-Up About Menstruation, EuRonews, (Aug. 19, 2021), https://www.euronews.com/2021/01/28/man-up-about-menstruation [https://perma.cc/CF8A-J4LS] ("Roughly 800 million girls and women menstruate every day. In too many countries and cultures, there's so much stigma attached to this basic, biological, function that girls dread their period. Why? Because they are cruelly ostracized.”).

${ }^{21}$ Nithin Srighar, Views of Menstruation in Religions and Cultures Around the World, INDIAFACTs (Apr. 19, 2016), http://indiafacts.org/views-of-menstruation-in-religions-and-cultures-around-the-world/ [https://perma.cc/YWJ6-JS6L].

${ }^{22}$ Eric Galatas, Most Bottled Water Comes from Tap, More Expensive than Gasoline, PuB. News SeRv. (Mar. 9, 2018), https://www.publicnewsservice.org/2018-03-09/water/study-most-bottled-water-comes-from-tapmore-expensive-than-gasoline/a61759-2 [https://perma.cc/VN2S-C5WE].

${ }^{23}$ Adrienne Matei, Bottled Water Drinkers READ THIS, WATER, INC. (Jan. 29, 2021), https://waterinc.com/drinking-bottled-water-read-this/ [https://perma.cc/9ES2-J74W]; Alex Sadler, The Overpriced Bottle Your Just Bought Is Probably Tap Water. Here's a Cheaper Alternative, ClaRK.com (Mar. 22, 2017), https://clark.com/deals-money-saving-advice/pepsi-aquafina-tap-water-best-bottled-waters/ [https://perma.cc/RKA7-FG4L].

${ }^{24}$ Andrew Adam Newman, A New Laundry Worry: Invisible Stains, N.Y. Times (Feb. 14, 2013), https://www.nytimes.com/2013/02/15/business/media/wisk-campaign-takes-on-invisible-laundry-stains.html
} 
Collar." ${ }^{25}$ His on-camera wife (or mother) would agonize and cringe, since of course she was in charge of the laundry and had obviously failed at it. ${ }^{26}$ Then an announcer would reassure her that "Wisk around the collar beats ring around the collar every time." ${ }^{27}$ For many years Wisk commanded a premium price compared with identical laundry detergent that was marketed under different trademarks. ${ }^{28}$ A 1984 New York Times article quoted Gloria Steinem saying of the extended "Ring Around the Collar" advertising campaign for Wisk: "The reform view is to tell him to wash his neck. The radical view is to tell him to wash his own shirt."29

[https://perma.cc/HF4R-ZBHD]; From Ring Around the Collar to 2012 Winner: Wisk Deep Clean Laundry Detergent Awarded Product of the Year, BUS. WIRE (Feb. 29, 2012),

https://www.businesswire.com/news/home/20120229005924/en/Ring-Collar-2012-Winner-Wisk\%C2\%AEDeep-Clean\%E2\%84\%A2 [https://perma.cc/P7KV-L9VE]; Randall Rothenberg, Thompson Gets Wisk, N.Y. TIMES (Aug. 14, 1989), https://www.nytimes.com/1989/08/14/business/the-media-business-advertisingthompson-gets-wisk.html [https://perma.cc/83VM-M3T2]; CONSUMER REPORTS, Wisk's Bubbly New Ad Campaign Targets Stains You Can't See, YAHOO! News (Feb. 20, 2013), https://www.yahoo.com/news/tagged/realestate/news/wisks-bubbly-ad-campaign-targets-stains-cant-see193000700.html [https://perma.cc/XU4A-YDKZ].

${ }^{25}$ See, e.g., Vintage Old 1970's Wisk Laundry Detergent Soap Ring Around the Collar Commercial, YouTuBE (June 6, 2013), https://www.youtube.com/watch?v=ZeakPcsccyY [https://perma.cc/9KD3-NSU3]; 1983 Wisk Detergent Ring Around the Collar Commercial, YouTuBE (Nov. 26, 2014), https://www.youtube.com/watch?v=ecUFX_u51AU [https://perma.cc/C7CA-T2DN]; 1977 Wisk Detergent Commercial (Toy Ring in the Box), YouTuBE (JAN. 9, 2011),

https://www.youtube.com/watch?v=n4HcxMz81-Q [https://perma.cc/Y38M-N9HE]; Commercial WiskRing Around the Collar (1979), YouTuBE (Oct. 14, 2009),

https://www.youtube.com/watch?v=0LgKsCDk0XE [https://perma.cc/9UTK-CB4R]; 1981 - No More Ring Around the Collar, YouTuBE (Sept. 12, 2016), https://www.youtube.com/watch?v=UYIN3Lh3rug [https://perma.cc/JQK2-CTYS]; 1979-1980 W.A. Powell's Laundry Detergent TV Commercial ("Ring Around the Collar"), YouTuBE (Dec. 11, 2020), https://www.youtube.com/watch?v=XGdEn3lw1-M [https://perma.cc/WG8W-UTDT]. In 1990 the ad campaign was "modernized" to "Ring Around the Collar was just the beginning": Tsk Tsk Tsk Wisk Wisk Wisk-1990, YouTuBE (Sept. 30, 2017), https://www.youtube.com/watch?v=6KV0Yi-9MDs [https://perma.cc/6VCA-Z6BL]; Wisk Commercial, YouTuBE (Dec. 18, 2007), https://www.youtube.com/watch?v=nrD3yjfvsUA [https://perma.cc/JE7Y-T4YT].

${ }^{26} I d$.

${ }^{27} I d$.

${ }^{28}$ Newman, supra note 24.

${ }^{29}$ Harold A. Klein, TOPICS, New York TimEs (June 10, 1984), https://www.nytimes.com/1984/06/10/nyregion/topics-250843.html [https://perma.cc/3ZU9-GJTC]. 


\section{The Word "Tampon" is a Low Value Trademark}

Whether a word can be a valid trademark is evaluated in context. Generic words cannot be monopolized as trademarks because competitors need to use them to describe their products. ${ }^{30}$ While "Tampax" can be, and is, a registered trademark for tampons, ${ }^{31}$ the word "tampon" cannot be a registered trademark for tampons. ${ }^{32}$ Any entity that sells tampons can call them tampons, so that consumers know what is inside the boxes or wrappers. In this context the word "tampon" is generic.

However, the word "tampon" can be, and is, a registered trademark for other goods and services. Yes few of the entities that registered "tampon" in some form as a trademark have had much business success: Registered trademarks using the word "tampon" for apparel, ${ }^{33}$ computer programs,${ }^{34}$ coloring books for children, ${ }^{35}$ Christmas tree ornaments, ${ }^{36}$ and a brand of wine stoppers ${ }^{37}$ have all gone "dead" on the principal registry ${ }^{38}$ for lack of use or maintenance. In an age of trademark depletion, where almost every word in the English language has been registered as a trademark multiple times, ${ }^{39}$

${ }^{30}$ Generic Terms Excluded From Trademark Protection, JusTiA (Apr. 2018), https://www.justia.com/intellectual-property/trademarks/strength-of-marks/generic-terms/ [https://perma.cc/V2JS-ST7G].

${ }^{31}$ TAMPAX - Trademark Details, JustiA (June 30, 2012), https://trademarks.justia.com/713/23/tampax71323876.html [https://perma.cc/VNY5-R9KD].

${ }^{32}$ See generally Lanham Trade-Mark Act of 1946, 50 Stat. 427 (July 5, 1946); Generic Trademark: Everything You Need to Know, UpCOUNSEL, https://www.upcounsel.com/generic-trademark [https://perma.cc/8X8K-VYZX].

${ }^{33}$ THE DISAPPROVING TAMPON, Registration No. 4,088,586.

${ }^{34}$ SMART TAMPON, Registration No. 5,723,970.

${ }^{35}$ U.S. Trademark Application Serial No. 87,421,747 (filed Apr. 23, 2017).

${ }^{36}$ U.S. Trademark Application Serial No. 77,321,246 (filed Nov. 5, 2007).

${ }^{37}$ U.S. Trademark Application Serial No. 90,473,852 (filed Jan. 19, 2021)

${ }^{38}$ Trademark/Service Mark Application, Principal Register, Version 5.8, U.S. PAT. \& TRAdEMARK OfF. (Jan. 25, 2017), https://www.uspto.gov/sites/default/files/documents/TEAS_RF.pdf [https://perma.cc/6FN6-KF55].

${ }^{39}$ An Inconvenient (Intellectual Property) Truth, NYU Law News (Feb. 9, 2018), https://www.law.nyu.edu/news/ideas/Barton-Beebe-Jeanne-Fromer-running-out-of-trademarks [https://perma.cc/DMQ9-3369]; Barton Beebe \& Jeanne C. Fromer, Are We Running Out of Trademarks? An Empirical Study of Trademark Depletion and Congestion, 131 HARV. L. REV. 945 (Feb. 2018); Jeanne 
the word "tampon" is notably unpopular. By way of comparison, searches of the USPTO database show only ten live marks using the words tampon or tampons ${ }^{40}$ while the word "comb" appears in two hundred and twenty-two live marks. ${ }^{41}$

\section{Trademarks and Branding Practices for Feminine Hygiene Products}

Like most health and beauty aids, menstrual products are generally much more alike than they are different. ${ }^{42}$ Purveyors of the various brands of tampons and sanitary pads try to distinguish their products using trademarks, advertising, and gimmickry. They are marketed based on attributes like purported absorbency, thickness, "invisibility" and comfort. They tout special features like "wings." And recently, both tampons and sanitary napkins are advertised as coming in a wide range of shapes and sizes. ${ }^{43}$

Some menstruation linked trademarks seem intended to invoke or blend in with other household products. For example, "Stay Free," 44 the trademark for a market dominant brand of sanitary napkins, is quite similar to "Cling Free," ${ }^{45}$ a trademark for sheets used to reduce static electricity and wrinkles while machine drying laundry. I have a vivid teenaged memory of my father lugging a basket of dirty clothes down the stairs and asking my mother in a shouty voice if she had remembered to buy Stay Frees. After the shock wore off, I had a very robust if nervous laughing fit.

Fromer \& Barton Beebe, The Future of Trademark Depletion in a Global, Multilingual Economy: Evidence and Lessons from the European Union.

${ }^{40}$ The author searched the USPTO database at http://tmsearch.uspto.gov/ on February 20, 2021 using the following search terms: tampon; tampons.

${ }^{41}$ The author searched the USPTO database at http://tmsearch.uspto.gov/ on February 21, 2021 using the following search terms: comb.

${ }^{42}$ See, e.g., Your nearest CVS, Walgreens or Rite Aid feminine hygiene aisle.

${ }^{43}$ See generally Umme Busra Fateha Sultana, The Imageries of Menstruation in Sanitary Napkin Ads: Representation and the Practice of Discourse as a Marketing Strategy, ADVERT. \& SOC'Y REV. 11.4 (2011).

${ }^{44}$ Stayfree Maxi Super Scented with Wings, JoHnSON \& JoHnson (2020), https://www.jnjconsumer.co.za/ourbrands/stayfree/pads/maxi-super/stayfree-maxi-super-scented-wings [https://perma.cc/G5JB-LH6F].

${ }^{45}$ Cling Free Sheets - Powder Fresh, RB, http://rbnainfo.com/product.php?productLineId=247 [https://perma.cc/LU32-VZ4N]. 
Other menstrual products manufacturers promote "health and wellness" messages with their trademarks and branding efforts. Contemporary advertisements for Playtex brand "Sport" tampons exhort menstruaters to exercise and be fit. ${ }^{46}$ One online advertisement features seven different trademark signifiers within a brief segment of text: "Playtex ${ }^{\circledR}$ Sport ${ }^{\circledR}$ Tampons PLAY ON ${ }^{\circledR}$ Playtex ${ }^{\circledR}$ Sport ${ }^{\circledR}$ has a $360^{\circ}{ }^{\circledR}$ design and FlexFit ${ }^{\circledR}$ technology that moves the way you move." ${ }^{" 17}$ The ad asserts: "These are great tampons for swimming, biking, running or whatever your activity of choice is." ${ }^{48}$ This is very similar to the upbeat message that o.b. brand tampons was telegraphing in the $1980 \mathrm{~s} ;{ }^{49}$ our tampon will help you remain active and fit during your periods, maybe even if you are not particularly active and fit the other days of the month. It was hard not to associate o.b. tampons with horseback riding on a beach.

Some of the trademarks deployed for sanitary napkins seem intended to blur with trademarks for products pitched at incontinence sufferers, as if any fluids leaking out of a female body ought to be handled the same way. The most common messages that trademarks promote for these products are respectability and secrecy. There are menstrual pads called "Whisper," perhaps to remind us to shut up and be quiet about our periods. ${ }^{50}$ Other trademarks for menstrual pads include "Security," "R1 "Radiant,"52 "Pure,"53 "Omni-

\footnotetext{
${ }^{46}$ See, e.g., Playtex Play On, PlAYTEX, https://www.playtexplayon.ca/ [https://perma.cc/S8GZ-U79P].

${ }^{47} I d$.

${ }^{48} I d$.

${ }^{49}$ Vintage 80's O.B. OB Tampons Commercial, YouTuBE (Aug. 4, 2009), https://www.youtube.com/watch?v=mVnvLwEOqJw [https://perma.cc/Z4RP-PYSG].

${ }^{50}$ Marketing Strategies of Whisper Brand, BRANDYUVA, https://brandyuva.in/2019/03/marketing-strategiesof-whisper.html [https://perma.cc/BWB3-VMHT]. Ironically, the company behind "Whisper" is engaged in an advertising campaign encouraging girls and women to "break the silence" about their periods. Id.

${ }^{51}$ Maxi Pads, U By Kotex, https://www.ubykotex.com/en-us/products/maxi-pads [https://perma.cc/V47M4ZUW].

${ }^{52}$ Radiant Pads, ALWAYs, https://always.com/en-us/shop-products/menstrual-pads/radiant-pads [https://perma.cc/7LNN-CSV2].

${ }^{53}$ Pure, ALWAYs, https://always.com/en-us/shop-products/menstrual-pads/pure [https://perma.cc/35SH9ZQY].
} 
Odor Guard Plus," and "Dignity" 59 are trademarks for bladder control pads. The trademark "Always" is used for both menstrual products and incontinence products, "Always" alone for sanitary napkins ${ }^{60}$ and "Always Discreet" for bladder control pads. ${ }^{61}$

The messages these trademarks send reflect an assumption that menstruators should be embarrassed into silence about menstruation as a cultural imperative, and as obedient capitalists we should purchase products that disguise everything related to our genitals with invisibility, and chemical perfume scents to mask our disgusting odors. Marketers generally favor the color blue when trademarking, branding, and packaging menstrual products, ${ }^{62}$ and use blue colored fluid to represent blood in advertisements. ${ }^{63}$ This is to

\footnotetext{
${ }^{54}$ Maxi Pads with Omni-Odor Guard Plus Long Lightly Scented, WALgreEns, https://www.walgreens.com/store/c/walgreens-maxi-pads-with-omni-odor-guard-plus-long-lightlyscented/ID=prod6188626-product [https://perma.cc/NR76-SWQF].

${ }^{55}$ SABA Ultra Invisible Ultra Thin Long with Wings, SABA, https://mysaba.com/products/saba_ultra_invisible_ultrathin_with_wings_heavy_flow [https://perma.cc/E9YL-DJN8].

${ }^{56}$ Poise Homepage, PoISE, https://www.poise.com/en-us [https://perma.cc/S8VC-X9NP].

${ }^{57}$ Bladder Control Pad-Ultimate, PREVAIL, https://www.prevail.com/products/female/bladder-control-padultimate [https://perma.cc/QLG7-GJQQ].
}

${ }^{58}$ H-E-B Reliance Underwear for Women, H-E-B, https://www.heb.com/product-detail/h-e-b-relianceunderwear-for-women-maximum-absorbency-small-medium/1424227 [https://perma.cc/MD8G-MMUJ].

${ }^{59}$ Bladder Control Pads - Dignity, HARTMANN, https://www.hartmann.info/en-us/our-products/incontinencemanagement/liners-and-bladder-control-pads/bladder-control-pads---dignity $\% \mathrm{C} 2 \% \mathrm{AE}$

[https://perma.cc/LQH4-ZCG9].

${ }^{60}$ Products - Menstrual Pads, ALwAys, https://always.com/en-us/shop-products/menstrual-pads [https://perma.cc/QE8K-YPDD].

${ }^{61}$ Using Our Incontinence Products, AlwAYs DisCREET, https://alwaysdiscreet.com/en-us/incontinenceadvice-support/incontinence-faqs/using-incontinence-products [https://perma.cc/4CT2-7A9L].

${ }^{62}$ See visuals at pages referenced by footnotes 31 through 42 .

${ }^{63}$ JR Thorpe, This Is the Actual Reason Pad Commercials Use That Weird Blue Liquid, BustLE (Oct. 20, 2017), https://www.bustle.com/p/why-do-period-product-commercials-use-blue-liquid-the-practice-has-along-bizarre-history-2957963 [https://perma.cc/B9CX-JE6G]; cf. Arti Patel, Kotex Breaks Tradition and Uses Blood-Like Liquid in New Ad, GLOB. News (Jan. 24, 2020), https://globalnews.ca/news/6457156/kotex-redliquid-ad/ [https://perma.cc/332K-9U4B]. 
dissuade the viewer from thinking about blood. ${ }^{64}$ "Using something that looks like actual blood to stand in for menstrual blood has been, in every preceding decade of tampon and pad advertisement, as completely off-limits as full-frontal nudity." ${ }^{.65}$

The same sort of blue fluid is also used to illustrate the capacity of disposable diapers. ${ }^{66}$ And because blue is used to represent boys in this culture, the choice of blue fluids suggests an effort to masculinize and mansplain menstruation, as well as to link sanitary products with diapers.

Relatively new are trademark and branding campaigns that utilize the color green to give their sanitary products an aura of environmentalism. Consumers are warned against "unnatural" menstrual products made with chlorine, plastics, rayon, and substandard inorganic cotton. These consumers are urged to instead buy products with trademarks like "Free and Clear," "E7 "ECO by Naty,"68 (which is also used for diapers), ${ }^{69}$ "Organyc,", and "Honest." for the health and wellbeing of the planet. It also primes people to be receptive to paying premium prices for "organic" products such as sanitary napkins made from organic cotton and recycled wood pulp. Ironically, many manufacturers market both natural and unnatural tampons and pads under different trademarks contemporaneously. For example,

${ }^{64}$ Thorpe, supra note 63.

${ }^{65} I d$.

${ }^{66}$ Id.; see also Andrew Adam Newman, Both Style and Substance in Diaper Advertising, N.Y. Times (May 24, 2010), https://www.nytimes.com/2010/05/25/business/media/25adco.html [https://perma.cc/J4PNBCH6]. For a satirical take on this phenomenon, see Cracked, If Tampon Ads Were Honest (Also Maxi Pads \& Other "Feminine Products"), YouTuBe (Dec. 4, 2017), https://www.youtube.com/watch?v=xi8u9DcC0_Q [https://perma.cc/2AED-9TT3].

${ }^{67}$ Free and Clear Ultra Thin Pads - Overnight (with Wings), Seventh Generation, https://www.seventhgeneration.com/free-clear-ultra-thin-pads-with-wings-overnight [https://perma.cc/Z99FDKBG].

${ }^{68}$ Sanitary Pads, ECO BY NATY, https://www.naty.com/us/en/for-women/sanitary-pads/ [https://perma.cc/5NPD-2JRW].

${ }^{69}$ Eco-Friendly Baby Diapers, ECO BY NATY, https://www.naty.com/us/en/for-baby/eco-diapers/eco-friendlybaby-diapers/31504.html [https://perma.cc/8XTU-CTX2].

${ }^{70}$ ORGANYC, https://www.organyc-online.com/home/ [https://perma.cc/2JZ5-N39Y].

${ }^{71}$ See Feminine Care, HoNEST, https://www.honest.com/personal-care-products/feminine-care-tamponsliners-pads [https://perma.cc/QL6G-7VHH]. 
o.b. makes an "organic" brand of tampons. ${ }^{72}$ Tampax markets its PURE line as " $100 \%$ Organic Cotton Core Tampons." 73 And Kotex has a product called "CleanWear."”74

\section{The Lanham Act ${ }^{75}$ Does Not Provide Tools for Addressing Sexist Trademarks}

Trademark law does not offer any legal tools for addressing misogynistic trademarks. This was made clear through extended trademark litigation concerning the registrability of racist trademarks. In the Harjo v. Pro Football series of cases, the validity of several "redskins" trademarks was challenged because "redskins" is unambiguously a racial slur. ${ }^{76}$ In 1992, a group of Native Americans filed a petition to cancel Redskins marks associated with the Washington Redskins NFL team. ${ }^{77}$ The Harjo plaintiffs argued that the marks were disparaging to a substantial composite of Native Americans in violation of Section 2(a) of the Lanham Act, which prohibits registration of a mark that "may disparage" persons or "bring them into contempt or disrepute."

Pro Football denied that the redskins marks were disparaging and asserted various affirmative defenses, including laches. ${ }^{79}$ In 1999, the Trademark Trial and Appeal Board (hereinafter TTAB), an independent administrative tribunal housed within the U.S. Patent $\&$ Trademark Office, held that the redskins marks were disparaging when they were

\footnotetext{
${ }^{72}$ See Organic Products, O.B., https://www.ob-tampons.com/feminine-products/organic [https://perma.cc/P3JC-5SBT].

${ }^{73}$ See Pure, TAMPAX, https://tampax.com/en-us/all-products/pure/ [https://perma.cc/Y33E-QQD3].

${ }^{74}$ See CleanWear, U ву KотEX, https://www.ubykotex.com/en-us/products/ultra-thin-period-pads/cleanwearpad-regular-with-wings [https://perma.cc/4VL2-SQ6B].

${ }^{75}$ See Legal Info. Inst., Lanham Act, CoRnell Law School (Mar. 7, 2021), https://www.law.cornell.edu/wex/lanham_act [https://perma.cc/SRY2-HTK9].

${ }^{76}$ See Alicia Jessop, Inside the Legal Fight To Change the Washington Redskins' Name, ForBEs (Oct. 15, 2013), https://www.forbes.com/sites/aliciajessop/2013/10/15/a-look-at-the-legal-fight-to-change-thewashington-redskins-name/?sh=299e697d4b20 [https://perma.cc/MP2B-9UXT]; Pro-Football, Inc. v. Harjo, 284 F. Supp. 2d 96 (D.D.C. 2003).

${ }^{77} \mathrm{Id}$.

${ }^{78} \mathrm{Id}$.

${ }^{79} \mathrm{Id}$.
} 
registered, and ordered the registrations canceled. ${ }^{80}$ Pro Football appealed to the District Court for the District of Columbia and ultimately the laches defense prevailed, so the D.C. Circuit never evaluated the TTAB's ruling that the Redskins marks were disparaging on the merits, but the dispute generated a lot of publicity. ${ }^{81}$

In the 2014 case Blackhorse v. Pro Football, the TTAB again decided to cancel trademark registrations for "Redskins" marks used by the National Football League and the Washington Redskins. ${ }^{82}$ After the cancellations of their registrations, the Washington Redskins could have continued to use their redskins marks as common law trademarks without interference from the Lanham Act. Registration is a tremendous benefit to trademark owners, however, and Pro Football fought hard to retain it. While the Blackhorse litigation was pending, the U.S. Supreme Court found that Section 2(a)'s limitations on disparaging marks was unconstitutional because the statutory provision violated the First Amendment. ${ }^{83}$ Without even going to court, Pro Football prevailed. ${ }^{84}$

The Supreme Court ruling on the unconstitutionality of Section 2(a) came in the 2017 case Matal v. Tam. ${ }^{85}$ In Tam, a band comprised of Asian musicians that called itself "The Slants" won the right to register "The Slants" as a trademark on the primary registry, even though one of its meanings was clearly racially disparaging. A 2019 follow up case, Iancu v. Brunetti, ${ }^{86}$ addressed whether Section 2(a)'s parallel prohibition on "immoral" or "scandalous" registrations could survive constitutional scrutiny after Tam. Rather unsurprisingly the Supreme Court decided that these limitations also violated the First Amendment, and Brunetti won the right to register "FUCT" as a trademark for a brand of

\footnotetext{
${ }^{80}$ See Blackhorse et al. v. Pro-Football, Inc., 111 U.S.P.Q.2d (BNA) 1080, 2014 WL 2757516 (T.T.A.B. June $18,2014)$.

${ }^{81}$ See Pro-Football, Inc. v. Harjo, 284 F. Supp. 2 d 96 (D.D.C. 2003).

${ }^{82}$ See Blackhorse et al. v. Pro-Football, Inc., 111 U.S.P.Q.2d (BNA) 1080, 2014 WL 2757516 (T.T.A.B. June 18, 2014); U.S. Pat. \& Trademark OfF., Media Fact SheEt (June 18, 2014), https://www.uspto.gov/sites/default/files/news/USPTO_Official_Fact_Sheet_on_TTAB_decision_in_Blackh orse_v_Pro_Football_Inc.pdf [https://perma.cc/T325-N3YD].

${ }^{83}$ Infra footnotes $60-62$.

${ }^{84} \mathrm{Id}$.

${ }^{85}$ See Matal v. Tam, 137 S. Ct. 1744 (2017).

${ }^{86}$ See Inacu v. Brunetti, 139 S. Ct. 2294 (2019).
} 
clothing. It was also notable, however, that during oral argument, none of the Supreme Court Justices was willing to say the word "FUCT" out loud. ${ }^{87}$

What the Harjo and Blackhorse lines of litigation did achieve, in conjunction with other types of relentless advocacy over decades, was to draw negative attention to the use of deeply racist trademarks. In 2005 the NCAA began to bring pressure on colleges and universities with racist mascots ${ }^{88}$, and eventually many were changed. ${ }^{89}$ In July of 2020 the NFL team in the national's capital announced that it would no longer be known as the Redskins. Instead, at least for now, it is the Washington Football Team. ${ }^{90}$ In the wake of George Floyd's murder by a police officer in Minnesota, having a racist trademark finally started to seem like a business liability to the team's owners. Other corporations have also started paying attention to the racist natures of their trademarks, and many have made changes. ${ }^{91}$

\footnotetext{
${ }^{87}$ See Jessica Gresko, In 'FUCT' Fashion Brand Case, Justices Avoid Saying Word, AP News (Apr. 15, 2019), https://apnews.com/article/north-america-us-news-ap-top-news-trademarks-courts0edae6b907fe47919085d8055b943476 [https://perma.cc/588C-LGHE].

${ }^{88}$ See The Associated Press, NCAA Takes Aim at Indian Mascots, CBS News (Aug. 5, 2005), https://www.cbsnews.com/news/ncaa-takes-aim-at-indian-mascots/ [https://perma.cc/4J4L-E98G].

${ }^{89}$ See Kevin Kaduk, 25 Colleges That Changed Their Native American Nicknames, MSN (July 3, 2020), https://www.msn.com/en-us/sports/ncaabk/25-colleges-that-changed-their-native-american-nicknames/ssBB16j7rw [https://perma.cc/6ELC-5T58].

${ }^{90}$ See Marguerite Ward \& Melissa Wiley, 15 Racist Brands, Mascots, and Logos That Were Considered Just Another Part of American Life, Business InSIDER (July 13, 2020), https://www.businessinsider.com/15racist-brand-mascots-and-logos-2014-6?op=1 [https://perma.cc/AFR7-KF6N].

${ }^{91}$ See e.g., Gillian Friedman, Here's What Companies Are Promising to Do to Fight Racism, N.Y. TimeS (Aug. 23, 2020), https://www.nytimes.com/article/companies-racism-george-floyd-protests.html [https://perma.cc/4PLE-6YQN]; Mike Rosenstein, Black Lives Matter, George Floyd Protests Ignite Calls for Logo, Mascot Changes at UNLV, Virginia, Texas A\&M, NJ (June 17, 2020), https://www.nj.com/rutgers/2020/06/black-lives-matter-george-floyd-protests-ignite-calls-for-logo-mascotchanges-at-unlv-virginia-texas-am.html [https://perma.cc/PMM6-AQDR]; Priya Elan, 'Woke' Fashion Brands Face Backlash for Not Practising What They Preach, The Guardian (June 13, 2020), https://www.theguardian.com/fashion/2020/jun/13/fashion-brands-culture-george-floyd [https://perma.cc/T6NJ-36SU]; Scottie Andrew \& Leah Asmelash, The Race-Related Things That Have Changed Since Protests Began Around George Floyd's Death, CNN (June 13, 2020), https://www.cnn.com/2020/06/13/us/changes-from-protests-george-floyd-trnd/index.html [https://perma.cc/LKP6-MA3L]; Marguerite Ward \& Melissa Wiley, 15 Racist Brands, Mascots, and Logos That Were Considered Just Another Part of American Life, BUSINESS InSIDER (July 13, 2020), https://www.businessinsider.com/15-racist-brand-mascots-and-logos-2014-6?op=1 [https://perma.cc/AFR7KF6N].
} 
Free speech absolutists were cheered by the outcomes of Tam and Brunetti at the Supreme Court. ${ }^{92}$ But one consequence of these holdings is that unambiguous hate speech can now become a federally registered trademark, endorsed and protected as such by the government of the United States, under the Lanham Act and via the Commerce Clause of the U.S. Constitution. Textual marks using the $\mathrm{N}$ word are now clearly registrable, and so are words like bitch, slut, cunt and whore. ${ }^{93}$

\section{CONCLUSION}

Common trademark and branding practices related to tampons and sanitary napkins treat having one's period as a problem that requires science, discretion, and a wide variety of products to address. They help to reinforce a culture of shame around menstruation. Based on recent litigation, it is now certain that the Lanham Act does not offer legal mechanisms by which to challenge the federal registration of sexist and gender-offensive trademarks.

As with racist trademarks, amplified criticism and persistent public pressure are the main mechanisms available to foment positive change in the marketplace for feminine hygiene products. Though contemporary trademark law does not provide any statutory tools with which to undermine the enforceability of sexist menstrual product trademarks, the inspiring examples provided by the triumph of energetic and sustained advocacy against racist trademarks offer a potential path forward. Feminists have a long history of challenging sexist advertising. But to successfully bring effective pressure to bear on companies that leverage misogyny in their trademarks and branding practices will require a lot of patience, and a lot of work. Consider this Essay a call to action.

\footnotetext{
${ }^{2}$ See Lisa Ramsey, Free Speech Challenges to Trademark Law After Matal v. Tam, 56 Houston L. Rev. 401 (2019); IPWatchdog, After Brunetti: The Trademark Bar Reacts to Fractured Decision, IPWATCHDOG (June 25, 2019), https://www.ipwatchdog.com/2019/06/25/brunetti-trademark-bar-weighs/id=110697/ [https://perma.cc/96V4-JGWS].

${ }^{93}$ See USPTO Tess trademark database: https://tmsearch.uspto.gov/bin/gate.exe?f=login\&p_lang=english\&p_d=trmk [https://perma.cc/U6M5VX2R].
} 